\title{
DNA sequence analysis suggests that cytb-nd1 PCR-RFLP may not be applicable to sandfly species identification throughout the Mediterranean region
}

\author{
Ivonne Pamela Llanes-Acevedo ${ }^{1}$ - Carolina Arcones ${ }^{1} \cdot$ Rosa Gálvez $^{2}$ - Oihane Martin ${ }^{2}$. \\ Rocío Checa $^{2}$ - Ana Montoya ${ }^{2}$ - Carmen Chicharro ${ }^{1}$ - Susana Cruz ${ }^{1}$. \\ Guadalupe Miró $^{2}$ - Israel Cruz ${ }^{3}$
}

Received: 13 October 2015 / Accepted: 30 November 2015 / Published online: 12 January 2016

(C) The Author(s) 2016. This article is published with open access at Springerlink.com

\begin{abstract}
Molecular methods are increasingly used for both species identification of sandflies and assessment of their population structure. In general, they are based on DNA sequence analysis of targets previously amplified by PCR. However, this approach requires access to DNA sequence facilities, and in some circumstances, it is time-consuming. Though DNA sequencing provides the most reliable information, other downstream PCR applications are explored to assist in species identification. Thus, it has been recently proposed that the amplification of a DNA region encompassing partially both the cytochrome- $B$ (cytb) and the NADH dehydrogenase 1 (ndl) genes followed by RFLP analysis with the restriction enzyme Ase I allows the rapid identification of the most prevalent species of phlebotomine sandflies in the Mediterranean region. In order to confirm the suitability of this method, we
\end{abstract}

Electronic supplementary material The online version of this article (doi:10.1007/s00436-015-4865-5) contains supplementary material, which is available to authorized users.

Ivonne Pamela Llanes-Acevedo

pamellanes@isciii.es

Carolina Arcones

c.arcones@isciii.es

Rosa Gálvez

r.galvez@ucm.es

Oihane Martin

oihane.martin.s@gmail.com

Rocío Checa

rocichec@ucm.es

Ana Montoya

amontoya@ucm.es

Carmen Chicharro

cchichar@isciii.es collected, processed, and molecularly analyzed a total of 155 sandflies belonging to four species including Phlebotomus ariasi, P. papatasi, P. perniciosus, and Sergentomyia minuta from different regions in Spain. This data set was completed with DNA sequences available at the GenBank for species prevalent in the Mediterranean basin and the Middle East. Additionally, DNA sequences from 13 different phlebotomine species (P. ariasi, $P$. balcanicus, $P$. caucasicus, $P$. chabaudi, P. chadlii, P. longicuspis, P. neglectus, P. papatasi, P. perfiliewi, P. perniciosus, $P$. riouxi, $P$. sergenti, and S. minuta), from 19 countries, were added to the data set. Overall, our molecular data revealed that this PCR-RFLP method does not provide a unique and specific profile for each phlebotomine species tested. Intraspecific variability and similar RFLP patterns were frequently observed among the

Susana Cruz

susi_11@hotmail.com

Guadalupe Miró

gmiro@ucm.es

Israel Cruz

isra.cruz@finddx.org

1 Servicio de Parasitología, Centro Nacional de Microbiología, Instituto de Salud Carlos III, World Health Organization Collaborating Center for Leishmaniasis, Ctra. Majadahonda-Pozuelo Km2, Majadahonda, 28220 Madrid, Spain

2 Departamento de Sanidad Animal, Facultad de Veterinaria, Universidad Complutense de Madrid, Avda. Puerta de Hierro s/n, 28040 Madrid, Spain

3 Neglected Tropical Diseases Programme, Foundation for Innovative New Diagnostics-FIND, Chemin des Mines 9, Campus Biotech, 1202 Geneva, Switzerland 
species tested. Our data suggest that this method may not be applicable throughout the Mediterranean region as previously proposed. Other molecular approaches like DNA barcoding or phylogenetic analyses would allow a more precise molecular species identification.

Keywords Mediterranean phlebotomine sandflies . Mitochondrial DNA $\cdot$ PCR-RFLP $\cdot c y t b$

\section{Introduction}

Hematophagous females of certain species of phlebotomine sandflies (Diptera: Psychodidae: Phlebotominae) are vectors of human and different animal pathogens worldwide (Pigott et al. 2014). They are responsible for the transmission of diseases caused by protozoans (Leishmania), viruses (Phlebovirus, Vesiculovirus, and Orbivirus), and bacteria (Bartonella bacilliformis) (Antoniou et al. 2008; Depaquit et al. 2010; Ready 2013; Maroli et al. 2013). (i) In the Mediterranean basin, different species of sandflies are vectors of Leishmania tropica, L. major, L. infantum, and $L$. donovani, the causative agents of leishmaniasis; (ii) the main viral diseases transmitted by phlebotomine sandflies in this region are caused by Phlebovirus (family Bunyaviridae), like the sandfly fever (SF) caused by the SF Sicilian virus and the SF Naples virus, as well as the summer meningitis caused by Toscana virus.

Both leishmaniasis and sandfly-borne viral diseases represent a serious threat to public veterinary health and are considered (re-)emerging infections in the Mediterranean area. Therefore, vector surveillance should be among the pillars of the activities devoted to the design and implementation of effective control measures against these diseases (WHO/ EMRO 2008; Depaquit et al. 2010; Charrel et al. 2012; Maroli et al. 2013; Antoniou et al. 2013; Ejov and Dagne 2014). Although fragile in nature, sandflies are able to adapt to a broad variety of environmental conditions including urban or peri-urban settings; the recent leishmaniasis outbreak in Madrid (Spain) is an example of this plasticity (Tarallo et al. 2010; Galvez et al. 2011; Carrillo et al. 2013; Ready 2013; Lisi et al. 2014). Their potential to spread to northern Europe cannot be omitted; the northward spread of leishmaniasis in Italy has been well documented, and the potential establishment of vector species in Germany is a cause of concern (Maroli et al. 2008; Biglino et al. 2010; Fischer et al. 2010; Melaun et al. 2014; Medlock et al. 2014). Due to their public health importance, surveillance of sandfly populations is critical to assess both their geographical distribution and that of the diseases they transmit, as well as routes of introduction to non-endemic areas.

As only some species of sandflies are confirmed vectors, an important aspect of surveillance is the appropriate identification of the obtained specimens. Traditionally, the identification of sandflies at species level has relied on the morphological analysis of anatomical structures such as the pharynx, spermathecae and cibarium of the females, and the terminal genitalia of the males (Killick-Kendrick et al. 1991). This approach requires a high degree of expertise and can be challenging when the specimens are not properly preserved. To contribute to this task, different molecular methods have been proposed as complementary approaches for specimen identification. It has been suggested that the amplification of a DNA target encompassing a fragment of the mitochondrial genes $c y t b$ and $n d l$ and the subsequent digestion of the amplicons with the endonuclease Ase I would be a useful tool for the rapid identification of the most common phlebotomine sandflies in the Mediterranean region (Latrofa et al. 2012). However, it is important to take into account that this study was based on specimens collected from a limited geographical area of Italy (Basilicata). In addition, in a recent report, Bounamous et al. (2014) failed to effectively distinguish some phlebotomine species in Algeria, even belonging to different genera (like $P$. ariasi and $S$. schwetzi).

In the present study, we aimed to assess whether the methodology proposed by Latrofa et al. (2012) was also useful for sandfly species identification in specimens from a wider geographical origin, including Spain and other endemic areas, where sandfly-borne diseases are endemic and entomological identification is required for surveillance.

\section{Material and methods}

We used two different approaches to test the PCR-RFLP protocol proposed by Latrofa et al. (2012). The first one consisted on a wet-lab PCR-Ase I RFLP analysis on selected representative sequences of each species collected in Spain (Assembly 1: phlebotomine sandflies from Spain $(N=155)$, see below); the second approach was an in silico analysis of the DNA sequences of the sandflies from assembly 1 plus a collection of 277 DNA sequences retrieved from the GenBank database belonging to 12 different species of sandflies that were collected by other authors in other Mediterranean and Middle East countries (Assembly 2: DNA sequences retrieved from the GenBank $(N=277)$, see below).

\section{Assembly 1: phlebotomine sandflies from Spain $(N=155)$}

The specimens of this assembly were captured at different sites from mainland Spain and the Balearic Islands between June and October 2013, at different time-points within the sandfly activity season in our region (May-October). The specimens were collected using CDC miniature light traps (John W. Hock, Company, Gainesville, FL) and stored in $70^{\circ}$ ethanol at $-20^{\circ} \mathrm{C}$ until further analyses. Sampling sites 
were selected according to the different bioclimatic zones in Spain (Fig. 1).

Both male and female were morphologically identified based on their genitalia. The pharyngeal armature and cibarium were also studied in the female specimens. The tip of the abdomen (between segments VI and VII) and head of the females were cutoff and cleared in Mark André medium (Abbonnenc 1972). The specimens were mounted onto glass slides in Hoyer medium (Upton 1993) and identified at species level, according to the taxonomic keys proposed by Gil et al. (1989). Mounted parts of the specimens were kept for future reference. As morphological identification was based on the study of the male genitalia and female head and spermatechae, the remaining of the body was kept at $-20{ }^{\circ} \mathrm{C}$ for DNA extraction and downstream molecular analyses. A detailed description of sampling locations, species (P. perniciosus, P. ariasi, P. papatasi, and S. minuta), and number of specimens included in assembly 1 is presented in Fig. 1 and Table 1.

\section{Assembly 2: DNA sequences retrieved from the GenBank $(N=\mathbf{2 7 7})$}

In order to increase our study sample and to complete the picture of representative sandflies in the Mediterranean region beyond the specimens captured in Spain (assembly 1), we retrieved from GenBank a total of 277 DNA sequences corresponding to 13 different phlebotomine species (P. ariasi, P. balcanicus, P. caucasicus, P. chabaudi, P. chadlii, P. longicuspis, $P$. neglectus, $P$. papatasi, P. perfiliewi, P. perniciosus, $P$. riouxi, $P$. sergenti, and $S$. minuta) containing the $c y t b-n d l$ sequence encompassed by the primers PhleF and PhleR described by Latrofa et al. (2011). These sequences were identified by BLASTn search using as query different DNA sequences obtained from specimens in assembly 1 . Alternatively, taxon-specific key (Phlebotomus, Sergentomyia) and gene identifier (cytb, cyt b, cyt-b, cytochrome $b$, cytochrome- $b$ ) were also used to search for candidate sequences. Selected DNA sequences included those from species endemic to the Mediterranean basin (including Italy and Algeria), the Middle East (Afghanistan and Iran), and other regions (Portugal) where the former species are also present. Details on the specimens included in assembly 2 are presented in Table 2. Further details related to these sequences are presented as supplementary material (Supplementary material 1).

\section{DNA extraction and cytb-nd1 PCR from assembly 1}

Genomic DNA was independently extracted from each specimen of assembly 1. Specimens were grinded and processed with the QIAamp DNA Mini Kit (QIAgen, Germany) in accordance with the manufacturer's instructions. DNA was eluted in $50 \mu \mathrm{L}$ of PCR-grade water and stored at $-20^{\circ} \mathrm{C}$.

The mitochondrial DNA target encompassing the $c y t b-n d 1$ region was amplified according to Latrofa et al. (2012) with minor modifications. Two microliters of DNA was used in a 25- $\mu \mathrm{L}$ final volume PCR reaction, including standard reaction buffer $2 \mathrm{mM} \mathrm{MgCl} 2,0.2 \mathrm{mM}$ each dNTP, and $0.7 \mathrm{U}$ of Thermus sp. DNA polymerase (Biotools, B\&M Labs, Spain), and 15 pmol of each primer PhleF (5'-AAT AAA TTA GGA GGA GTA ATT GC-3') and PhleR (5'-GCC TCG AWT TCG WTT ATG ATA AAT T-3') (Sigma-Genosys).

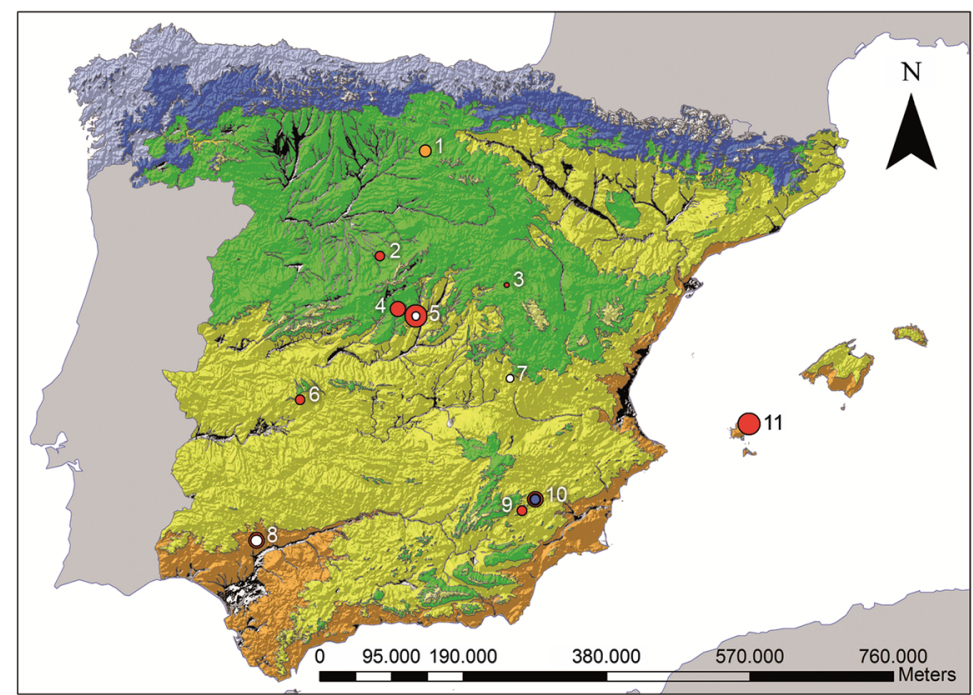

\section{BIOCLIMATES}

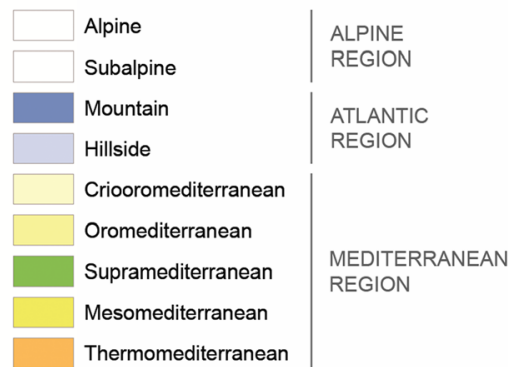

$\begin{array}{ll}\text { Species } & \mathbf{N}^{0} \text { specimens } \\ \text { O P. perniciosus } & \circ 1 \\ \text { O P. ariasi } & \circ 2-10 \\ \text { - P. papatasi } & \bigcirc 11-20 \\ \text { ○ } \text { S. minuta } & \bigcirc 21-40\end{array}$

Fig. 1 Geocoded surveyed sites and number of sandflies collected shown on a bioclimatic zone map of Spain. Numbers indicate sampling locations: Agés (Burgos) (1), Escarabajosa de Cabezas (Segovia) (2), Zaorejas (Guadalajara) (3), Majadahonda (Madrid) (4), Vicálvaro (Madrid) (5), Cañamero (Cáceres) (6), Buenache de Alarcón (Cuenca)
(7), Castilblanco de los Arroyos (Sevilla) (8), Achivel (Murcia) (9), Moratalla (Murcia) (10), and San Joan de Labritja (Ibiza) (11). Colored filled circles indicate phlebotomine species. Circle size indicates the number of specimens according to the scale shown 
Table 1 Description of sampling locations, species, and number of specimens included in assembly $1(N=155)$

\begin{tabular}{|c|c|c|c|c|c|}
\hline Province & Site & Date (dd/mm/yyyy) & Coordinates & Species & $\begin{array}{l}\text { No. of specimens } \\
\text { (male/female) }\end{array}$ \\
\hline Burgos & Agés & $15 / 08 / 2013$ & $42.37 \mathrm{~N} 3.49 \mathrm{~W}$ & P. ariasi & $12(12 / 0)$ \\
\hline Segovia & Escarabajosa de Cabezas & $15 / 08 / 2013$ & $41.10 \mathrm{~N} 4.20 \mathrm{~W}$ & P. perniciosus & $7(7 / 0)$ \\
\hline Guadalajara & Zaorejas & $06 / 07 / 2013$ & $39.38 \mathrm{~N} 5.40 \mathrm{~W}$ & P. perniciosus & $1(1 / 0)$ \\
\hline Madrid & Majadahonda & $08 / 08 / 2013$ & $40.48 \mathrm{~N} 3.91 \mathrm{~W}$ & P. perniciosus & $18(18 / 0)$ \\
\hline Madrid & Vicálvaro & $07 / 10 / 2013$ & $40.40 \mathrm{~N} 3.62 \mathrm{~W}$ & P. perniciosus & $21(17 / 4)$ \\
\hline Madrid & Vicálvaro & $07 / 10 / 2013$ & $40.40 \mathrm{~N} 3.62 \mathrm{~W}$ & S. minuta & $1(1 / 0)$ \\
\hline Cuenca & Buenache de Alarcón & $15 / 08 / 2013$ & $39.65 \mathrm{~N} 2.16 \mathrm{~W}$ & S. minuta & $1(1 / 0)$ \\
\hline Cáceres & Cañamero & $03 / 08 / 2013$ & $39.38 \mathrm{~N} 5.40 \mathrm{~W}$ & P. perniciosus & $3(1 / 2)$ \\
\hline Murcia & Archivel & $23 / 07 / 2013$ & $38,07 \mathrm{~N} 2.00 \mathrm{~W}$ & P. perniciosus & $8(3 / 5)$ \\
\hline Murcia & Moratalla & $23 / 07 / 2013$ & $39.02 \mathrm{~N} 1.49 \mathrm{E}$ & P. perniciosus & $17(3 / 14)$ \\
\hline Murcia & Moratalla & $23 / 07 / 2013$ & $39.02 \mathrm{~N} 1.49 \mathrm{E}$ & P. papatasi & $2(2 / 0)$ \\
\hline Murcia & Moratalla & $23 / 07 / 2013$ & $39.02 \mathrm{~N} 1.49 \mathrm{E}$ & S. minuta & $3(3 / 0)$ \\
\hline Sevilla & Castilblanco de los Arroyos & $24 / 06 / 2013$ & $37.69 \mathrm{~N} 6.00 \mathrm{~W}$ & P. perniciosus & $11(10 / 1)$ \\
\hline Sevilla & Castilblanco de los Arroyos & $24 / 06 / 2013$ & $37.69 \mathrm{~N} 6.00 \mathrm{~W}$ & S. minuta & $10(10 / 0)$ \\
\hline Ibiza & Sant Joan de Labritja & $01 / 10 / 2013$ & $39.02 \mathrm{~N} 1.49 \mathrm{E}$ & P. perniciosus & $40(38 / 2)$ \\
\hline
\end{tabular}

Phlebotomine sandflies captured in Spain, June-October 2013

Amplification was performed on a 9800 Fast Thermal Cycler (Applied Biosystems), standard ramp enabled, with the following conditions: initial denaturation of $5 \mathrm{~min}$ at $94{ }^{\circ} \mathrm{C}, 40$ cycles at $94{ }^{\circ} \mathrm{C}$ for $1 \mathrm{~min}, 52{ }^{\circ} \mathrm{C}$ for $1 \mathrm{~min}$, and $72{ }^{\circ} \mathrm{C}$ for $1 \mathrm{~min}$, and final extension at $72{ }^{\circ} \mathrm{C}$ for $10 \mathrm{~min}$. All the amplified products were resolved on $2 \%$ agarose gels stained with Pronasafe Nucleic Acid Staining (Laboratorios CONDA, Spain) and visualized under UV light.

\section{Ase I RFLP analysis}

Selected representative amplicons obtained at the cytb-ndlPCRs from assembly 1 were digested with the endonuclease Ase I as described by Latrofa et al. (2012). Digested products were resolved on $2 \%$ agarose gels as described above and their sizes estimated by comparison to a 100-bp DNA ladder (Nippon Genetics, Europe GmbH).

\section{DNA sequencing}

Both strands of the cytb-ndl PCR products from assembly 1 were sequenced in duplicate using the same PCR primer set. The Big-Dye Terminator Cycle Sequencing Ready Reaction Kit V3.1 and the automated ABI PRISM 377 DNA sequencer (Applied Biosystems, Foster City, CA) were used. Sequences obtained were analyzed and edited using the software Molecular Evolutionary Genetics Analysis (MEGA) version 5.2 (Tamura et al. 2011).

\section{Alignment and trimming of the DNA sequences from assembly 1 and assembly 2}

DNA sequences generated from the 155 sandfly specimens collected in Spain (assembly 1) and the 277 DNA sequences obtained from the GenBank (assembly 2) were loaded in MEGA 5.2 and aligned using the ClustalW algorithm (Thompson et al. 1994). The sequences were trimmed to the cytb-ndl sequence flanked by the primers $\mathrm{PhleF}$ and PhleR. A P. perniciosus DNA sequence retrieved from the GenBank (Accession Number JF766956) was used as reference sequence to guide both alignment and trimming. Minor editing to complete the 3'end was conducted in some cases, provided all other specimens of the same species had identical sequence. Primer sequences were added to the end of each sequence to simulate the PCR product.

\section{In silico Ase I RFLP}

A virtual Ase I RFLP was performed on all trimmed sequences flanked by the $\mathrm{PhleF} / \mathrm{PhleR}$ primers from assemblies 1 and 2 using the program NEBcutter V2.0 from NEW ENGLAND BioLabs ${ }^{\circledR}$ Inc. (Vincze et al. 2003). which allows to produce theoretical digests with restriction enzymes. Settings for the enzyme Ase I included a virtual run of the digested products on a $2 \%$ agarose gel and the full resolution of a 100-bp ladder for DNA sizing, $L=70 \mathrm{~mm}$. 
Table 2 Description of the sampling location, species, and number of specimens included in assembly $2(N=277)$, for which $c y t b-n d 1$ sequences were retrieved from the GenBank

\begin{tabular}{ll}
\hline $\begin{array}{l}\text { Species } \\
\text { No. of specimens) }\end{array}$ & $\begin{array}{l}\text { Country } \\
\text { (No. of specimens) }\end{array}$ \\
\hline P. perniciosus (26) & Italy (6), Malta (3), Portugal (6), Spain (1), Tunisia (9), Italy/Malta/Tunisia (1) \\
P. longicuspis (6) & Morocco (1), Tunisia (5) \\
P. ariasi (45) & Algeria (1), France (10), Portugal (8), Spain (26) \\
P. papatasi (31) & Afghanistan (4), Cyprus (2), Egypt (5), Iran (1), Israel (3), Italy (8), Jordan (1), Palestine (3), Syria (2), Turkey (2) \\
P. chabaudi (32) & Algeria (5), Tunisia (27) \\
P. neglectus (6) & Italy (6) \\
P. perfiliewi (26) & Algeria (4), Greece (5), Italy (17) \\
P. riouxi (13) & Algeria (9), Tunisia (4) \\
P. sergenti (57) & Greece (1), Iran (48), Lebanon (1), Morocco (1), Sria (1), Tunisia (4), Turkey (1) \\
P. chadlii (2) & Algeria (2) \\
P. balcanicus (2) & Iran (2) \\
P. caucasicus (25) & Afghanistan (4), Iran (21), \\
S. minuta (6) & Italy (6)
\end{tabular}

Sandflies were captured from 1997 to2003, according to the information provided by the authors in the sequence identifiers or its associated publication (information available in Supplementary material 1)

${ }^{a}$ The sequence was associated to these three countries by its authors

\section{Results}

The sequences corresponding to a total of 432 sandfly specimens (assemblies 1 and 2) were tested by the cytb-nd1-PCR Ase I-RFLP method in silico. In addition, a subset of sequences of assembly 1 was also experimentally assessed. Overall, this study covered 13 sandfly species from five different subgenera: 249 Larroussius specimens (152 P. perniciosus, 6 P. longicuspis, 57 P. ariasi, 26 P. perfiliewi, 2 P. chadlii, 6 P. neglectus), 33 Phlebotomus specimens (P. papatasi), 127 Paraphlebotomus specimens (57 P. sergenti, 13 P. riouxi, 32 P. chabaudi, 25 P. caucasicus), 2 Adlerius specimens (P. balcanicus), and 21 Sergentomyia specimens (S. minuta).

\section{cytb-nd1-PCR and experimental Ase I RFLP on specimens from assembly 1}

DNA from all specimens in assembly 1 was successfully amplified using the $c y t b-n d 1$-PCR method. Obtained amplicon sizes ranged from 472 to 482 bp depending on the phlebotomine species considered (Online Resource 2). Ase I RFLP analysis was conducted in a limited number of DNA isolates corresponding to representative haplotypes. In all cases, the digested PCR products showed identical restriction patterns to those predicted by the in silico analysis (Fig. 2a, b). Interestingly, Ase I RFLP profiles for $P$. ariasi-variant 1 and P. perniciosus-variant 2 produced a practically identical pattern comprising bands of 26 and $c 455 \mathrm{bp}$. On the other hand, P. perniciosus variant 1 returned a distinct pattern with two bands of approximately 100 and $350 \mathrm{bp}$. The $P$. papatasi specimen yielded a band of $c 375 \mathrm{bp}$, whereas $S$. minuta generated a c230-bp band (Fig. 2 and Table 3).

\section{Alignment and trimming of cytb-nd1 DNA sequences from specimens included in assemblies 1 and 2}

A final alignment was built with the 155 DNA sequences generated from the assemblies 1 and 2. The alignment (primer sequences included) encompasses the nucleotides at positions 440 to 920 of the P. perniciosus sequence used as reference (GenBank Acc no. JF766956) and comprises cytochrome $b$ gene (partial cds), $t R N A$-Ser (complete sequence), and NADH dehydrogenase subunit 1 gene (partial cds). DNA sequence analysis showed a different PCR product size for each species, ranging from 472 to $491 \mathrm{bp}$. This is mainly due to the sequence length variability of the intergenic mitochondrial DNA spacer-1 (Igs1), lying between cytb gene and $t R N A$ Ser (Supplementary material 2).

The 155 DNA sequences from assembly 1 were deposited in GenBank under the following accession numbers: P. perniciosus KP685413-KP685538, P. ariasi KP685539KP685550, P. papatasi KP702248 and KP702249, and $S$. minuta KP702250-KP702264.

\section{In silico assessment of Ase I RFLP profiles on cytb-nd1 DNA sequences obtained from assemblies 1 and 2}

The theoretical in silico Ase I RFLP analysis performed on the 432 cytb-nd1 DNA sequences, comprising 13 different 
a

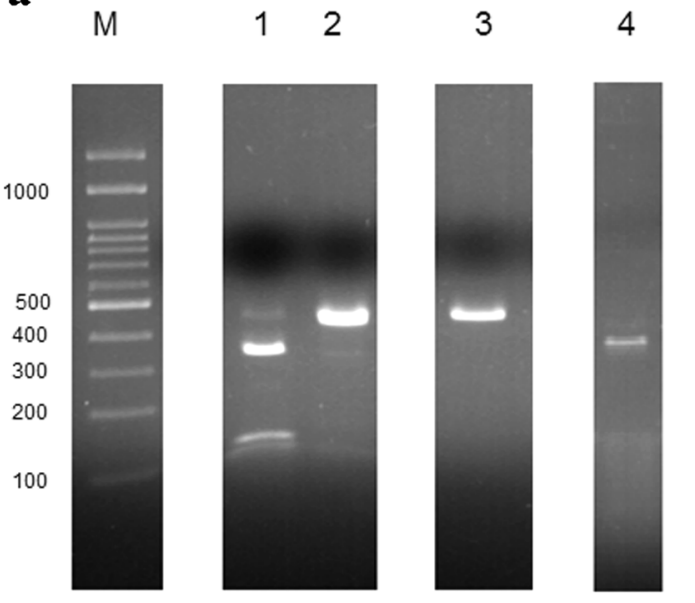

Fig. 2 Ase I RFLP patterns of the cytb-nd1 PCR products on selected representative sequences of each species collected in Spain (assembly 1). A 100-bp ladder (lane M), P. perniciosus variant 1 (lane 1), P. perniciosus variant 2 (lane 2), P. ariasi variant 1 (lane 3), P. papatasi (lane 4), and

sandfly species, returned 16 (I-XVI) different RFLP profiles. A virtual image of the 16 RFLP patterns is given in Supplementary material 3 . Specific details for each specimen are provided in online resource 1 . These results were identical b

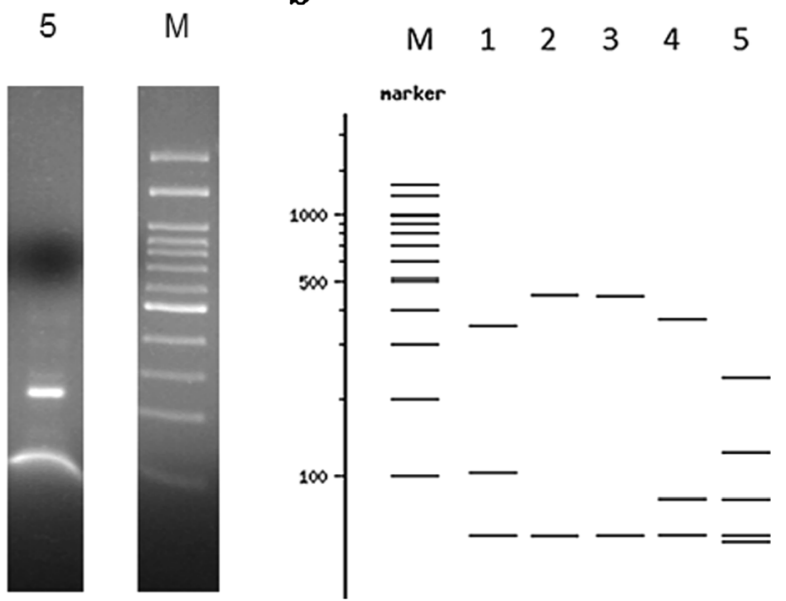

S. minuta variant-2 (lane 5). a Wet-lab PCR-Ase I RFLP analysis and $\mathbf{b}$ in silico Ase I RFLP pattern based on the cytb-nd1 DNA sequence of the specimens assessed in a using NEBcutter V2.0 software

to those obtained by experimental Ase I RFLP on the selected subset of sandfly specimens from assembly 1 (Fig. 2a, b).

Single, but not necessarily distinctive, RFLP patterns were obtained in all specimens from the following species:

Table 3 Summary of patterns obtained by AseI RFLP analysis with the 432 DNA sequences considered in this study

\begin{tabular}{|c|c|c|c|c|c|c|c|}
\hline \multirow{2}{*}{$\begin{array}{l}\text { Assigned Ase } \\
\text { I pattern } \\
\text { I }\end{array}$} & \multirow{2}{*}{$\begin{array}{l}\text { Species }^{\mathrm{a}} \\
\text { P. perniciosus } 1\end{array}$} & \multicolumn{2}{|c|}{ Specimens } & \multirow{2}{*}{$\begin{array}{l}\text { No. of } \\
\text { cuts }\end{array}$} & \multirow{2}{*}{$\begin{array}{l}\text { Restriction bands (b.p.) } \\
26,104,351\end{array}$} & \multirow{2}{*}{$\begin{array}{l}\begin{array}{l}\text { Restriction bands } \\
\text { (Latrofa et al. 2012) }\end{array} \\
28,104,351\end{array}$} & \multirow{2}{*}{$\begin{array}{l}\begin{array}{l}\text { Length } \\
\text { sequence (b.p.) }\end{array} \\
481\end{array}$} \\
\hline & & 152 & 151 & & & & \\
\hline II & P. perniciosus_2 & & 1 & 1 & 26,455 & & \\
\hline III & P. longicuspis_l & 6 & 5 & 3 & $26,90,104,261$ & ND & \\
\hline I & P. longicuspis_2 & & 1 & 2 & $26,104,351$ & & \\
\hline IV & P. ariasi_1 & 57 & 56 & 1 & 26,454 & ND & 480 \\
\hline $\mathrm{V}$ & P. ariasi_2 & & 1 & 2 & $26,178,276$ & & \\
\hline VI & P. papatasi & 33 & & 2 & $26,72,374$ & $28,72,374$ & 472 \\
\hline VII & P. riouxi & 13 & & 1 & 26,446 & ND & \\
\hline VII & P. balcanicus & 2 & & 1 & 26,446 & ND & \\
\hline VII & P. chabaudi_l & 32 & 31 & 1 & 26,446 & ND & \\
\hline VIII & P. chabaudi_2 & & 1 & 2 & $26,57,389$ & ND & \\
\hline IX & P. neglectus & 6 & & 1 & 26,465 & 28,645 & 491 \\
\hline$X$ & P. perfiliewi & 26 & & 3 & $26,90,104,260$ & $28,90,104,260$ & 480 \\
\hline XI & P. sergenti_1 & 57 & 52 & 1 & 26,450 & ND & 476 \\
\hline XII & P. sergenti_2 & & 5 & 2 & $26,206,244$ & & \\
\hline XIII & P. chadlii & 2 & & 1 & 26,451 & ND & 477 \\
\hline XI & P. caucasicus_1 & 25 & 1 & 1 & 26,450 & ND & 476 \\
\hline XIV & P. caucasicus_2 & & 24 & 2 & $26,214,236$ & & \\
\hline XV & S. minuta_1 & 21 & 16 & 5 & $17,26,40,72,91,236$ & $17,29,72,130,236$ & 482 \\
\hline XVI & S. minuta_2 & & 5 & 4 & $17,26,72,131,236$ & & \\
\hline
\end{tabular}

Information regarding phlebotomine species number of specimens and predicted size of digested products and length of sequences are provided for direct comparison purposes

$N D$ no data

${ }^{a}$ Including species variants in some phlebotomine species analyzed in this study 
P. papatasi (pattern VI), P. neglectus (IX), P. perfiliewi (X), $P$. riouxi (VII), P. chadlii (XIII), and P. balcanicus (VII). Among all species, only $P$. papatasi gave a unique species-specific pattern that could be unequivocally differentiated. In addition, $P$. riouxi and $P$. balcanicus shared a single RFLP pattern (VII) that was also identical to the variant 1 observed in 31 out of 32 specimens of $P$. chabaudi. The remaining species presented two distinctive patterns each: P. perniciosus (151 specimens assigned to pattern I, and the remaining one to pattern II), $P$. ariasi (56 pattern IV, one pattern V), $P$. longicuspis (5 pattern III, one pattern I), P. chabaudi (31 pattern VII, one pattern VIII), P. sergenti (52 pattern XI, 5 pattern XII), P. caucasicus (24 pattern XIV, one pattern XI), and $S$. minuta (16 pattern XV, 5 pattern $\mathrm{XVI})$.

Seven species could not be accurately differentiated due to shared RFLP patterns. Thus, pattern I was common to 151 P. perniciosus and one P. longicuspis, pattern VII was common to all $P$. riouxi, P. balcanicus, and 31 out of 32 $P$. chabaudi, and pattern XI was common to one P. caucasicus and 52 out of 57 P. sergenti. In addition to this, a number of in silico RFLP patterns were very similar, but not identical. These included pattern III $(26,90,104$, $261 \mathrm{bp}$ ) obtained in 5/7 P. longicuspis and pattern X (26, $90,104,260 \mathrm{bp}$ ) from all $P$. perfiliewi analyzed, and also patterns II $(26,455$ bp) in $1 / 152$ P. perniciosus, IV (26, $454 \mathrm{bp})$ in $56 / 57$ P. ariasi, VII $(26,446 \mathrm{bp})$ in $31 / 32$ P. chabaudi, $13 / 13$ P. riouxi, and $2 / 2$ P. balcanicus, IX (26, $465 \mathrm{bp})$ in 6/6 P. neglectus, XI (26, $450 \mathrm{bp})$ in 52/57 P. sergenti and $1 / 25$ P. caucasicus, and XIII (26, $451 \mathrm{bp})$ in 2/2 P. chadlii (Fig. 3 ).

\section{Discussion}

Sequence analysis of a cytb gene region from 13 different sandfly species provides in silico and experimental evidence demonstrating that the $c y t b-n d 1$ PCR-RFLP assay may not be applicable to phlebotomine species identification throughout the Mediterranean region as initially proposed by other authors. Our data confirm that it is not possible to obtain a unique, distinctive RFLP pattern for each individual sandfly species tested excluding P. papatasi and S. minuta. We found a significant proportion of species returning identical or almost undistinguishable RFLP profiles. This fact would represent a pitfall for vector incrimination in regions where two coendemic species share the same or almost identical RFLP pattern. This is the case for P. perniciosus pattern II and $P$. ariasi pattern IV, both identified in Spanish specimens, being both vector of $L$. infantum. Importantly, this lack of discriminatory power has been previously reported using the same methodology by Bounamous et al. (2014). In that survey, the authors were unable to effectively discriminate among 17 sandfly species present in Algeria, even when a double digestion with Ase I and $\mathrm{Mnl}$ I restriction enzymes was used.

It is important to take into consideration that the study by Latrofa et al. (2012) was restricted to sandfly specimens from the south of Italy. In our subset of Italian specimens $(n=6)$ from the same area, we found similar findings except for S. minuta. Therefore, pattern XVI (the one showed by Latrofa et al. 2012) was identified in 5 S. minuta specimens, whereas the remaining one (Gen Bank Acc no. JF766981) presented pattern $\mathrm{XV}$, as in all $15 \mathrm{~S}$. minuta specimens from Spanish origin.
Fig. 3 In silico Ase I RFLP analysis obtained with NEBcutter V2.0 showing RFLP patterns that are similar or almost undistinguishable. Patterns are indicated in Roman numerals at the bottom of the image. The virtual run shows the digested products on a theoretical $2 \%$ agarose gel and the full resolution of a 100-bp ladder.

P. longicuspis_1 (lane 1),

P. perfiliewi (lane 2),

P. pernicious_2(lane 3),

P. ariasi_1 (lane 4), P. chabaudi

1 (lane 5$)$, P. riouxi (lane 6),

P. balcanicus (lane 7),

P. neglectus (lane 8), P. sergenti_ 1 (lane 9), P. caucasicus_1(lane 10), and P. chadlii (lane 11)

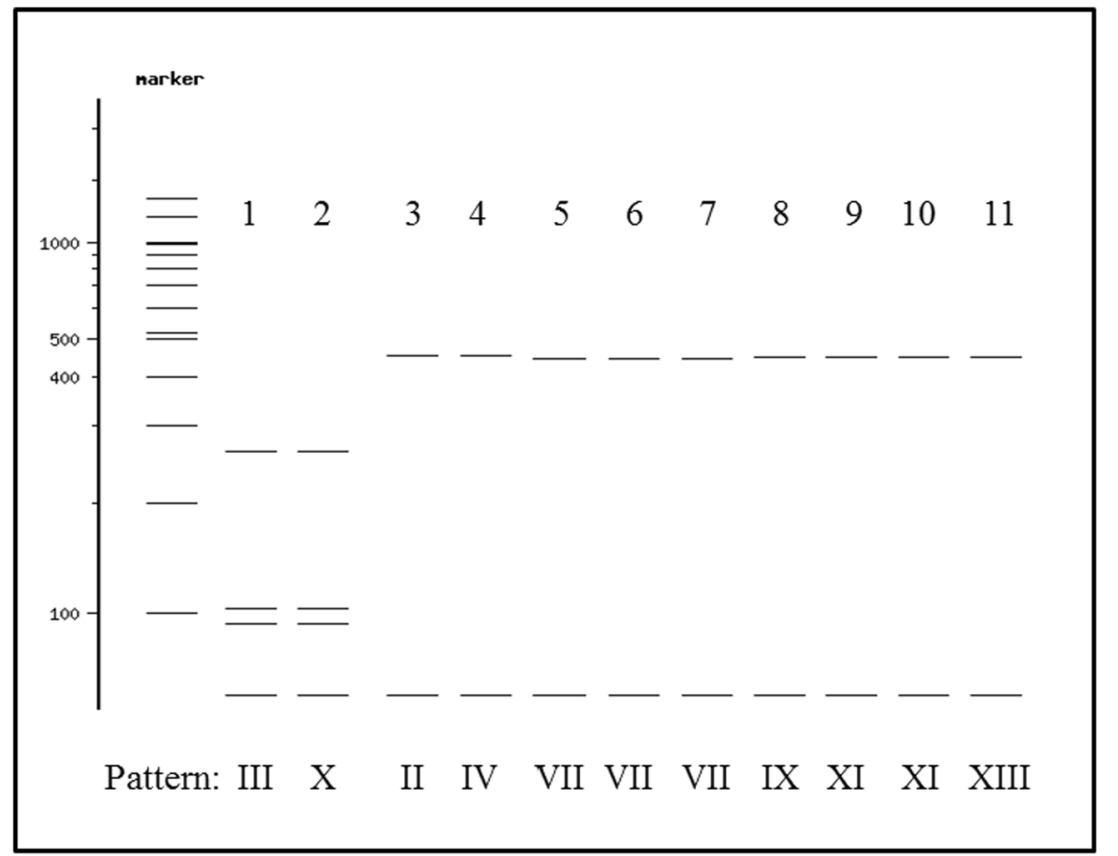


The similarity of certain RFLP patterns would be particularly problematic for phlebotomine species identification if the patterns correspond to sympatric species. This seems to be the case for Algeria and Tunisia, where P. longicuspis and $P$. perfiliewi are coendemic and thought to be potential vectors of L. infantum (Ready 2013). Discrimination between both species in these countries would be very difficult to achieve if we obtain patterns III (as in five out of six P. longicuspis in this work) or X (in all 26 P. perfiliewi studied here). In this study, one Moroccan P. longicuspis specimen showed PCRRFLP pattern I, as did the majority of the P. perniciosus specimens analyzed. These two species coexist in several countries and are remarkably similar morphologically. In Spain, where only $P$. longicuspis male specimens have been described so far, the presence of $P$. longicuspis and P. perniciosus has been questioned (Guernaoui et al. 2005).

On the other hand, the similarity found among patterns II (in 1/152 P. perniciosus), IV (in 56/57 P. ariasi), VII (in 31/32 $P$. chabaudi, P. riouxi, and P. balcanicus), and IX (P. neglectus) would impair the definitive identification due to geographical distribution overlapping between $P$. ariasi and $P$. perniciosus; this would be particularly important in Italy, where $P$. ariasi, P. perniciosus, and $P$. neglectus coexist. Although $P$. ariasi and $P$. perniciosus are proven vectors of $L$. infantum, this is not the case of P. neglectus (Ready 2013). It is important to point out that $P$. riouxi and $P$. chabaudi are similar from the morphological and taxonomic point of view. Both species are known to occur sympatrically in some geographical regions including Algeria and Tunisia. According to our sequence analysis data, no significant differences were found at the nucleotide level to conclusively consider $P$. riouxi and $P$. chabaudi as independent species, as previously proposed by Bounamous et al. (2014). This notion is also supported by the phylogenetic data obtained with other molecular markers, including cytb and elongation factor $1-\alpha$ (Tabbabi et al. 2014). Overall, this information provides molecular and evolutionary evidence suggesting that $P$. riouxi should be considered either as a synonym or as a subspecies of $P$. chabaudi.

Pattern VII was the only profile shared by two different subgenera (Paraphlebotomus and Adlerius). Thus, it would be useful to analyze the RFLP patterns in other sandfly species belonging to Adlerius subgenus endemic to the Mediterranean basin. Similarity between patterns XI (in 52/57 P sergenti and in 1/25 P. caucasicus) and XIII ( $P$. chadlii) would be also a problem regarding sandfly identification because these three phlebotomine species coexist in some geographical areas (see www.sandflycatalog. org). Whereas $P$. sergenti is a proven vector of $L$. tropica (Ready 2013). this potential role has also been suggested for P. caucasicus (Artemiev 1978; Killick-Kendrick 1999). However, P. chadlii has not been described as suitable vector of the disease to date.
An important contribution of this work is the submission to the GenBank of 155 new DNA sequences for thecytb-ndl region from Spanish specimens, including 126 P. perniciosus sequences to be added to the single sequence already available at GenBank from this country. Additionally, a total of 15 new $S$. minuta sequences add to the only six previously available sequences, all corresponding to Italian specimens.

Our results demonstrate that neither in Spain nor throughout the Mediterranean region is possible to accurately differentiate phlebotomine sand flies using the $c y t b-n d 1$ PCR-RFLP method. Because sequences from Middle East countries were underrepresented in this study, we cannot draw definitively conclusions on the performance of this method with samples from regions other than the Mediterranean basin. Nevertheless, further work at the subregional level is needed to confirm the extent of these findings. Taking into account the sequence variability observed within the cytb-ndl region, we believe that a phylogenetic analysis or a DNA barcoding approach would allow more precise species identification, as it has been proposed by other authors (Esseghir et al. 1997; Bounamous et al. 2008; Kruger et al. 2011; Latrofa et al. 2011). Nevertheless, before these approaches are fully developed, they should be based on a solid morphological identification of the specimens.

Acknowledgments This work was supported in part by Instituto de Salud Carlos III (MPY-1248/12) grant and (PI14CIII/00016) funded by AESI'. Ivonne Pamela Llanes-Acevedo was granted a student fellowship by COLCIENCIAS/COLFUTURO. Our sincere gratitude to the managers of the sampling sites for their permission to set the CDC light traps. With special thanks to Little "Luke" Herrero for identifying good positions to set up the CDC traps in the "Era Alcalade," Agés allowing us to get some nice $P$. ariasi. We also thank Silvia Miguelañez for her kind support collecting the sandflies specimens from Segovia.

Author contribution Conceived and designed study: IC and IPLLA. Performed the experiments: IPLLA, CA, and SC. Analyzed data: IPLLA, $\mathrm{CA}, \mathrm{CCH}, \mathrm{SC}$, and IC. Contributed reagents/sandflies/methods: RG, OM, RCH, AM, GM, IPLLA, CCH, and IC. Wrote the paper: IPLLA and IC.

\section{Compliance with ethical standards}

Conflict of interest The authors declare that they have no conflict of interest.

Open Access This article is distributed under the terms of the Creative Commons Attribution 4.0 International License (http:// creativecommons.org/licenses/by/4.0/), which permits unrestricted use, distribution, and reproduction in any medium, provided you give appropriate credit to the original author(s) and the source, provide a link to the Creative Commons license, and indicate if changes were made.

\section{References}

Abbonnenc E (1972) Les phlébotomes de la región éthiopienne (Diptera, Psychodidae). Mémories ORSTOM 55:1-289 
Antoniou M, Haralambous C, Mazeris A, Pratlong F, Dedet JP, Soteriadou K (2008) Leishmania donovani in Cyprus. Lancet Infect Dis 8:6-7

Antoniou M, Gramiccia M, Molina R, Dvorak V, Volf P (2013) The role of indigenous phlebotomine sandflies and mammals in the spreading of leishmaniasis agents in the Mediterranean region. Euro Surveill 18:20540

Artemiev MM (1978) Sandflies (Diptera, Psychodidae, Phlebotominae) of Afghanistan Kabul: Ministry of Public Health

Biglino A, Bolla C, Concialdi E, Trisciuoglio A, Romano A, Ferroglio E (2010) Asymptomatic Leishmania infantum infection in an area of northwestern Italy (Piedmont region) where such infections are traditionally nonendemic. J Clin Microbiol 48:131-136

Bounamous A, Boudabous R, Jouet D, Augot D, Ferté H, Babba H, Berchi S, Depaquit J (2008) Molecular and morphological characterisation of two closely related species belonging to the subgenus Phlebotomus chabaudi Croset, Abonnenc \& Rioux, 1970 et $P$. riouxi Depaquit, Killick-Kendrick \& Léger, 1998 (Diptera: Psychodidae). Parasite 15:565-571

Bounamous A, Lehrter V, Hadj-Henni L, Delecolle JC, Depaquit J (2014) Limits of a rapid identification of common Mediterranean sandflies using polymerase chain reaction-restriction fragment length polymorphism. Mem Inst Oswaldo Cruz 109:466-472

Carrillo E, Moreno J, Cruz I (2013) What is responsible for a large and unusual outbreak of leishmaniasis in Madrid. Trends Parasitol 29: $579-580$

Charrel RN, Bichaud L, de Lamballerie X (2012) Emergence of Toscana virus in the Mediterranean area. World J Virol 1:135-141

Depaquit J, Grandadam M, Fouque F, Andry PE, Peyrefitte C (2010) Arthropod-borne viruses transmitted by Phlebotomine sandflies in Europe: a review. Euro Surveill 15:19507

Ejov M, Dagne D (2014) Strategic framework for leishmaniasis control in the WHO European Region 2014-2020. World Health Organization Regional Office for Europe, Copenhagen

Esseghir S, Ready PD, Killick-Kendrick R, Ben-Ismail R (1997) Mitochondrial haplotypes and phylogeography of Phlebotomus vectors of Leishmania major. Insect Mol Biol 6:211-225

Fischer D, Thomas SM, Beierkuhnlein C (2010) Temperature-derived potential for the establishment of phlebotomine sandflies and visceral leishmaniasis in Germany. Geospat Health 5:59-69

Galvez R, Descalzo MA, Guerrero I, Miro G, Molina R (2011) Mapping the current distribution and predicted spread of the leishmaniosis sand fly vector in the Madrid region (Spain) based on environmental variables and expected climate change. Vector Borne Zoonotic Dis 11:799-806

Gil CJ, Morillas MF, Sanchis Marin MC (1989) Los flebótomos en España. Rev Sanid Hig Publica 63:15-34

Guernaoui S, Pesson B, Boumezzough A, Pichon G (2005) Distribution of phlebotomine sandflies, of the subgenus Larroussius, in Morocco. Med Vet Entomol 19:111-115

Killick-Kendrick R (1999) The biology and control of phlebotomine sand flies. Clin Dermatol 17:279-289

Killick-Kendrick R, Tang Y, Killick-Kendrick M (1991) The identification of female sandflies of the subgenus Larroussius by the morphology of the spermathecal ducts. Parassitologia 33(Suppl):335-347

Kruger A, Struven L, Post RJ, Faulde M (2011) The sandflies (Diptera: Psychodidae, Phlebotominae) in military camps in northern Afghanistan (2007-2009), as identified by morphology and DNA 'barcoding'. Ann Trop Med Parasitol 105:163-176
Latrofa MS, Dantas-Torres F, Weigl S, Tarallo VD, Parisi A, Traversa D, Otranto D (2011) Multilocus molecular and phylogenetic analysis of phlebotomine sand flies (Diptera: Psychodidae) from southern Italy. Acta Trop 119:91-98

Latrofa MS, Annoscia G, Dantas-Torres F, Traversa D, Otranto D (2012) Towards a rapid molecular identification of the common phlebotomine sand flies in the Mediterranean region. Vet Parasitol 184:267-270

Lisi O, Urso D, Vaccalluzzo V, Bongiorno G, Khoury C, Severini F, Di Muccio T, Gramiccia M, Gradoni L, Maroli M (2014) Persistence of phlebotomine Leishmania vectors in urban sites of Catania (Sicily, Italy). Parasit Vectors 7:560

Maroli M, Rossi L, Baldelli R, Capelli G, Ferroglio E, Genchi C, Gramiccia M, Mortarino M, Pietrobelli M, Gradoni L (2008) The northward spread of leishmaniasis in Italy: evidence from retrospective and ongoing studies on the canine reservoir and phlebotomine vectors. Trop Med Int Health 13:256-264

Maroli M, Feliciangeli MD, Bichaud L, Charrel RN, Gradoni L (2013) Phlebotomine sandflies and the spreading of leishmaniases and other diseases of public health concern. Med Vet Entomol 27:123-147

Medlock JM, Hansford KM, Van BW, Zeller H, Alten B (2014) A summary of the evidence for the change in European distribution of phlebotomine sand flies (Diptera: psychodidae) of public health importance. J Vector Ecol 39:72-77

Melaun C, Kruger A, Werblow A, Klimpel S (2014) New record of the suspected leishmaniasis vector Phlebotomus (Transphlebotomus) mascittii Grassi, 1908 (Diptera: Psychodidae: Phlebotominae) the northernmost phlebotomine sandfly occurrence in the Palearctic region. Parasitol Res 113:2295-2301

Pigott DM, Bhatt S, Golding N, Duda KA, Battle KE, Brady OJ, Messina JP, Balard Y, Bastien P, Pratlong F, Brownstein JS, Freifeld CC, Mekaru SR, Gething PW, George DB, Myers MF, Reithinger R, Hay SI (2014) Global distribution maps of the leishmaniases. Elife 3

Ready PD (2013) Biology of phlebotomine sand flies as vectors of disease agents. Annu Rev Entomol 58:227-250

Tabbabi A, Rhim A, Ghrab J, Martin O, Aoun K, Bouratbine A, Ready PD (2014) Phlebotomus (Paraphlebotomus) riouxi: a synonym of Phlebotomus chabaudi without any proven vectorial role in Tunisia and Algeria. Med Vet Entomol 28(Suppl 1):51-59

Tamura K, Peterson D, Peterson N, Stecher G, Nei M, Kumar S (2011) MEGA5: molecular evolutionary genetics analysis using maximum likelihood, evolutionary distance, and maximum parsimony methods. Mol Biol Evol 28:2731-2739

Tarallo VD, Dantas-Torres F, Lia RP, Otranto D (2010) Phlebotomine sand fly population dynamics in a leishmaniasis endemic periurban area in southern Italy. Acta Trop 116:227-234

Thompson JD, Higgins DG, Gibson TJ (1994) CLUSTAL W: improving the sensitivity of progressive multiple sequence alignment through sequence weighting, position-specific gap penalties and weight matrix choice. Nucleic Acids Res 22:4673-4680

Upton M (1993) Aqueous gum-chloral slide mounting media: an historical review, vol 83, Bulletin Entomol Res. Division of Entomology CSIRO, Canberra, pp 267-274

Vincze T, Posfai J, Roberts RJ (2003) NEBcutter: a program to cleave DNA with restriction enzymes. Nucleic Acids Res 31:3688-3691

World Health Organization Regional Office for the Eastern Mediterranean (WHO EMRO) (2008) Report on the intercountry meeting on leishmaniasis control strategies in the Eastern Mediterranean Region. 1:22. Aleppo, Syrian Arab Republic 